University of Wollongong

Research Online

Faculty of Engineering and Information

Faculty of Engineering and Information

Sciences - Papers: Part A

Sciences

$1-1-2014$

Investigation of closure of internal cracks during rolling by FE model considering crack surface roughness

\title{
Hailiang Yu
}

University of Wollongong, hailiang@uow.edu.au

A Kiet Tieu

University of Wollongong, ktieu@uow.edu.au

Cheng Lu

University of Wollongong, chenglu@uow.edu.au

Ajit R. Godbole

University of Wollongong, agodbole@uow.edu.au

Follow this and additional works at: https://ro.uow.edu.au/eispapers

Part of the Engineering Commons, and the Science and Technology Studies Commons

Research Online is the open access institutional repository for the University of Wollongong. For further information contact the UOW Library: research-pubs@uow.edu.au 


\title{
Investigation of closure of internal cracks during rolling by FE model considering crack surface roughness
}

\author{
Abstract \\ Internal cracks often appear in cast slabs, and their evolution during hot deformation directly affects the \\ product quality. In this paper, the authors investigate the closure behavior of internal cracks during plate \\ rolling using a finite element (FE) model that takes into account the roughness of the crack surface. \\ Influences of the roughness and reduction ratio on the closure of cracks are analyzed. The simulated \\ results show that the models with consideration of the initial crack roughness can be used to investigate \\ the formation of residual voids around the crack after rolling. The simulation results are validated by \\ experimental observations. Finally, we propose an explanation of the crack closure mechanism during \\ rolling.

\section{Keywords} \\ internal crack, crack closure, surface roughness, rolling, finite element simulation \\ Disciplines \\ Engineering | Science and Technology Studies

\section{Publication Details} \\ Yu, H., Tieu, A. K., Lu, C. \& Godbole, A. R. (2014). Investigation of closure of internal cracks during rolling \\ by FE model considering crack surface roughness. International Journal of Advanced Manufacturing \\ Technology, 75 (9-12), 1633-1640.
}




\title{
Investigation of closure of internal cracks during rolling by FE model considering crack surface roughness*
}

\author{
Hailiang $\mathrm{YU}^{1,2}$, A Kiet TIEU ${ }^{1}$, Cheng LU ${ }^{1}$, Ajit GODBOLE ${ }^{1}$ \\ 1. School of Mechanical, Materials \& Mechatronics Engineering, University of Wollongong, NSW 2500, Australia \\ 2. School of Mechanical Engineering, Shenyang University, Shenyang 110044, China
}

\begin{abstract}
Internal cracks often appear in cast slabs, and their evolution during hot deformation directly affects the product quality. In this paper, the authors investigate the closure behavior of internal cracks during plate rolling using a Finite Element (FE) model that takes into account the roughness of the crack surface. Influences of the roughness and reduction ratio on the closure of cracks are analyzed. The simulated results show that the models with consideration of the initial crack roughness can be used to investigate the formation of residual voids around the crack after rolling. The simulation results are validated by experimental observations. Finally, we propose an explanation of the crack closure mechanism during rolling.
\end{abstract}

Keywords: internal crack; crack closure; surface roughness; rolling; finite element simulation

\section{Introduction}

Internal cracks often occur in continuous cast slabs (Fig. 1) due to local non-uniform deformation, shrinkage, etc [1-3]. These cracks must be closed in the subsequent hot rolling process to ensure high quality of the product. If the cracks are not closed and healed in the hot rolling process, their behavior during subsequent processes may have an adverse impact on the product, resulting in the rejection of the product. If the cracks go undetected, there is potential for a significant risk. In the rolling process, there are some favorable factors which promote crack closure and healing. The hot rolling temperature ranges from $1000^{\circ} \mathrm{C}$ to $1200^{\circ} \mathrm{C}(0.6 \sim 0.8$ of the melting temperature). In this temperature range, the atoms have great ability to migrate and the energy of crack surfaces is large, which improves the tendency for crack healing.

The behavior of cracks in materials under large plastic deformation has been investigated using the Finite Element Method (FEM). Features such as surface longitudinal cracks [4-7], surface

\footnotetext{
* Corresponding author: YU HL, E-mail: hailiang@uow.edu.au or yuhailiang1980@tom.com
} 
transversal cracks [8-12], edge cracks [13-18], corner cracks [19-20] and internal cracks [1] have been studied. Ervasti and Ståhlberg [9] simulated and analyzed the crack closure as well as growth of longitudinal and transversal surface cracks of different dimensions in the flat slab rolling process with different roll radii and friction coefficients. Yukawa et al [10] analyzed the deformation of micro-cracks in the rolling process using a two-dimensional rigid-plastic FEM code. Yu et al [19] simulated the behavior of transversal cracks in the corner of a slab in vertical and horizontal rolling processes by a three-dimensional FEM. They applied the contact pressure on the crack boundary to determine the crack shape and crack tip stress in order to analyze the closure and growth of cracks. Deng et al [1] simulated the evolution of internal cracks in the rolling process under various reduction ratios and deformation characteristics. However, to date there have been no reports on the study of internal crack closure, considering the effect of crack surface roughness.

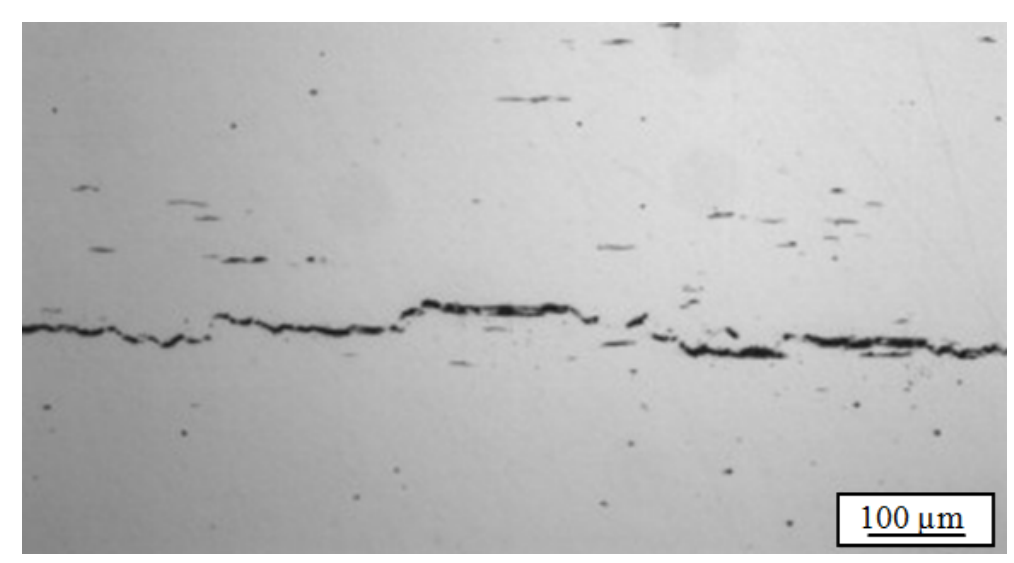

Fig. 1 Internal cracks in slabs

Besides the studies on crack closure, some research has been carried out on the closure of voids during plastic deformation [21-29]. Nakasaki et al [21] introduced the integration of hydrostatic stress into the description of void closure at the center of a slab during rolling. They found that the cross-sectional area of the pore is proportional to the hydrostatic pressure in single-pass rolling. Jeong et al [22] used a modified Gurson model that incorporated damage accumulation under shear and compression to predict void closure in sintered material under compressive loading. Zhang et al $[\mathbf{2 3}, \mathbf{2 4}]$ developed an analytical model for the closing of a spherical void during axial compression of a cylinder. They used a 'meso-mechanics' approach to investigate this problem. A 
cell model was adopted to analyze the evolution of the void, arriving at a criterion for void closure. Using the criterion for void closure, process design and optimization in cast ingots could be conveniently carried out while ensuring the elimination of voids. The FE method was also used to simulate the closure of voids during plastic deformation [27-29]. Kakimotoa et al [27] used both two-dimensional and three-dimensional FE analyses to study the closure of centerline voids during axial compression and side pressing of forgings with circular and rectangular cross-sections. They proposed a criterion for void closure considering the effective strain, effective stress, hydrostatic stress as well as some flow properties of the material. Lee et al [28] used an FE model for void closure and measured the void size before and after the upsetting process using an X-ray scanner. Chen et al [29] developed a nonlinear-coupled FE model to investigate the deformation mechanism of internal void defects during plastic deformation. The predicted reductions for central longitudinal voids in hot rolling processes are in good agreement with experimental findings. The above studies have assumed that the voids are either circular or elliptic in shape, which makes it difficult to predict the residual voids.

In this paper, the authors present an FE model that takes into account the crack surface roughness to analyze their evolution during rolling. The calculated results are compared with experimental observations. The comparisons show that the model considering the crack surface roughness is more accurate for prediction of the closure behavior of internal cracks.

\section{Numerical simulation}

In this study, we have assumed that the cracks occur in the plate center, as has been commonly observed in continuous slabs [1]. In the simulation, $450 \mathrm{~mm}$ diameter work rolls are considered as rigid. The plate thickness is $40 \mathrm{~mm}$ before rolling. The surface profile is chosen as a sinusoidal wave as in Eq. (1) $[\mathbf{3 0}, \mathbf{3 1}]$ :

$$
y=\frac{W_{D}}{2}\left\{1-\cos \left(\frac{2 \pi x}{W_{L}}\right)\right\}
$$

where, $W_{D}$ is the roughness depth, $W_{L}$ is roughness wavelength, and $W_{D}=\mathrm{A} W_{L}, \mathrm{~A}$ is a factor coefficient. Fig. 2 shows a schematic diagram of an internal crack. In the current version of the model, the crack length $\left(C_{L}\right)$ is set as $1 \mathrm{~mm}, W_{L}$ is set as $30 \mu \mathrm{m} . W_{D}$ is artificially chosen as 1,4 and $24 \mu \mathrm{m}$ to analyze the influence of crack surface roughness on the closure of cracks over a wide range of values. The corresponding values of $\mathrm{A}$ are $0.03,0.13$ and 0.8 respectively. In the 
experiments, a preset crack of roughness Ra1.6 is used to validate the FE model, in which the ratio $\left(\mathrm{A}=W_{D} / W_{L}\right)$ is 0.8 . And the crack depth $\left(C_{D}\right)$ is half of $W_{D}$. During rolling, the rolling reduction ratio is set as $20 \%, 30 \%$ and $50 \%$.

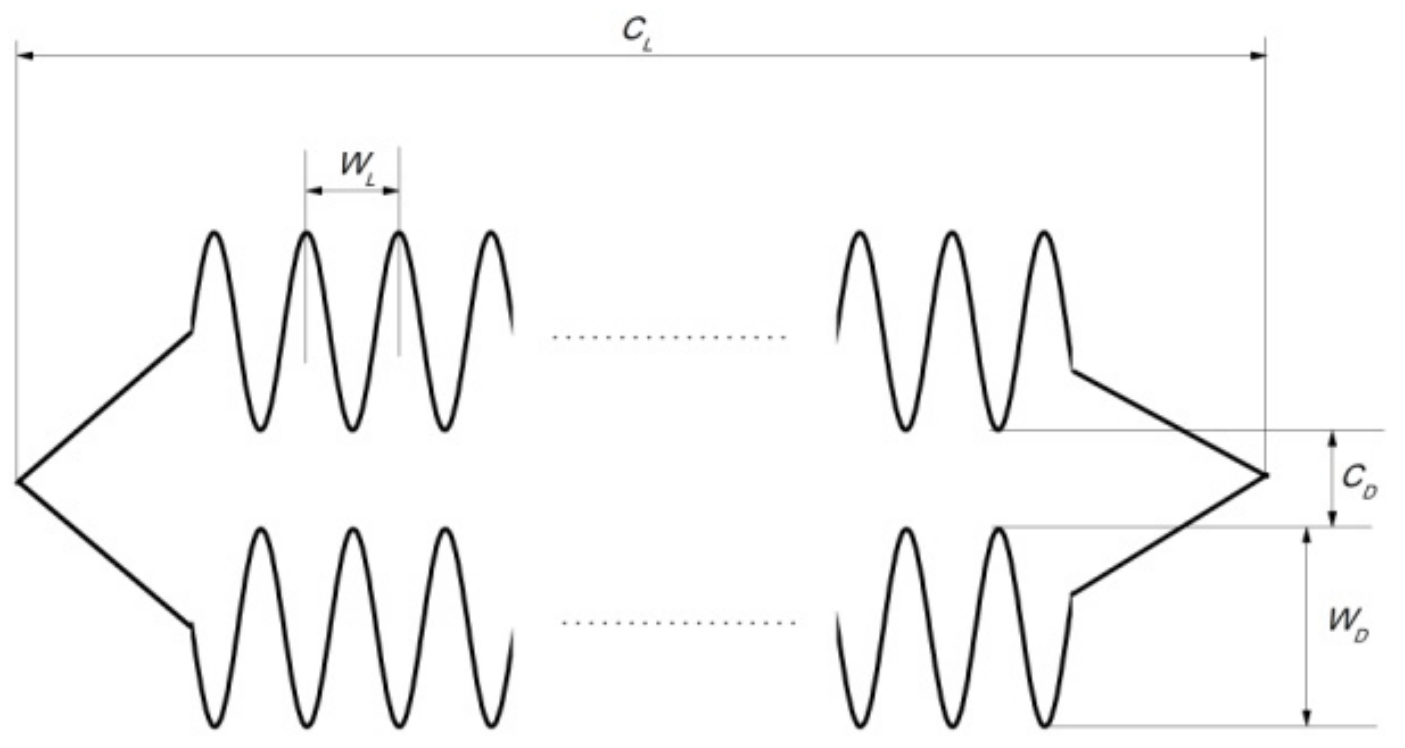

Fig. 2 Schematic diagram of an internal crack profile with sinusoidal roughness (before rolling)

In the models, the rolls are assumed rigid, and the plate is represented by a bilinear isotropic material model. The yield stress is calculated by $\sigma_{0}=\mathrm{A} \varepsilon^{\mathrm{B}} \dot{\varepsilon}^{\mathrm{C} T+\mathrm{D}} e^{\mathrm{FT}}$ [32]. This equation is obtained by curve-fitting actual measured values of carbon steel with the chemical composition C 0.18, Si 0.32 and Mn 0.82 under different values of true strain $\varepsilon$, strain rate $\dot{\varepsilon}$ and deformation temperature T. The constants A, B, C, D and F are 1715.7 MPa.s, $0.17,0.17^{\circ} \mathrm{C}^{-1}, 0.05$ and -0.26 ${ }^{\circ} \mathrm{C}^{-1}$ respectively [6]. In the rolling process, the temperature is set at $1150^{\circ} \mathrm{C}$. The change in the plate temperature is neglected in the calculation of the yield stress of the plate.

Because crack closure is mainly a surface phenomenon, a two-dimensional analysis assuming a plane stress state is usually adequate to simulate the onset of crack closure. Two-dimensional geometrical models of the plate with an internal crack before rolling are established with the above parameters and computational meshes with quadrilateral elements of plane strain formulation were created on the platform of LS-DYNA. Fig. 3 shows the FE meshing of a plate with an internal crack before rolling. The elements around the internal crack are much finer than elsewhere in order to accommodate the steeper gradients in parameters. The size of the elements around the crack is set as $1.6 \mu \mathrm{m}$. In the model, there are 46875 elements and 51084 nodes. In the 
rolling process, the rolls rotate with a constant angular speed $(6.2 \mathrm{rad} / \mathrm{s})$. The plate enters the gap between the rolls with an initial velocity of $1.4 \mathrm{~m} / \mathrm{s}$ and exits under the action of friction force between the roll and the plate. The Coulomb friction model is employed for dealing with the contacts. For the plate rolling with flat roll, it is recommended that the friction coefficient be in the range from 0.27 to 0.40 [33]. In this study, the friction coefficient is set at 0.35 [6].

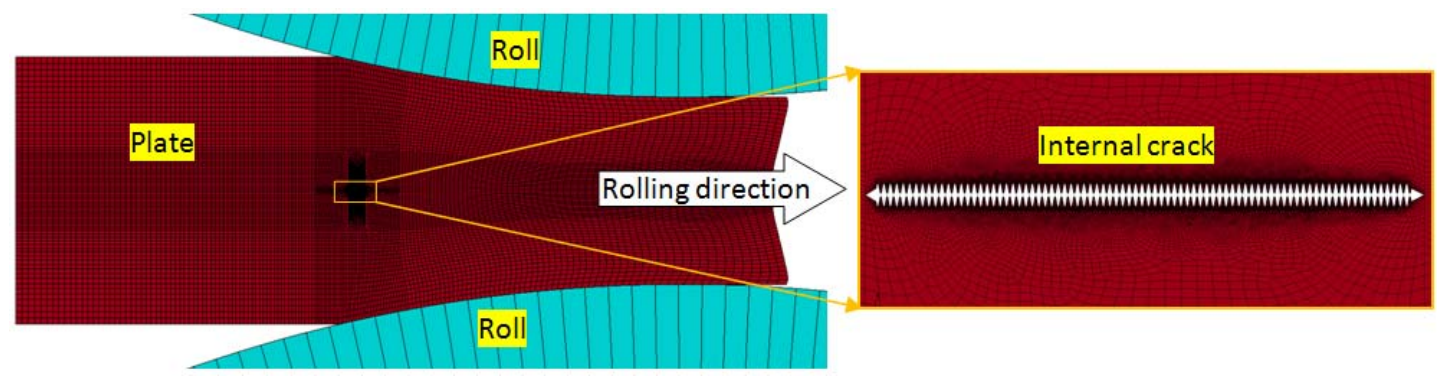

Fig. 3 Geometry and FE meshing of plate with an internal crack with surface roughness

\section{Results}

Figures 4(a) to 4(d) show the evolution of crack shapes and the equivalent strain distribution in the internal crack region at different cross sections in the rolling deformation zone when the reduction ratio is $30 \%$. When the crack enters the rolling deformation zone (Fig. 4(a)), the peaks of the crack surface first make contact, the crack develops into many smaller voids. With progressive movement to positions "b" and "c", the size of the voids in the wave troughs gradually decreases until they are eventually eliminated. After rolling, there still are small voids in the sample at the wave peaks owing to insufficient rolling reduction, and the residual void size is about $1.6 \mu \mathrm{m}$. In the rolling deformation zone, the equivalent strain in a plate without any defect is relatively uniform. However, as seen in Fig. 4, the initial presence of the crack renders the equivalent strain in the rolling deformation zone non-uniform. The equivalent strain reaches 2.1 around the crack roughness peaks, and it is zero in the vicinity of the roughness troughs. With movement of crack from "a" to "c", the maximum value of equivalent strain gradually increases. From "c" to "d", the change of equivalent strain distribution is negligible.

Figures 5(a), 5(b) and 5(c) show the equivalent strain distribution and the void shape in the internal cracks region after rolling, under different rolling reduction ratios of $20 \%, 30 \%$ and $50 \%$. When the reduction ratio is $20 \%$, there are many voids peak zones after rolling. With higher 
reduction ratio, the number of residual voids decreases after rolling. When the reduction ratio is $50 \%$, the crack appears to be completely healed as shown in Fig. 5 (c). The change in size of the residual voids after rolling is shown in Fig. 5(d). The higher the rolling reduction ratio, the higher the maximum equivalent strains. The maximum equivalent strain is 2.4 when the reduction ratio is $20 \%$, while 2.8 for $30 \%$ and 3.4 for $50 \%$.
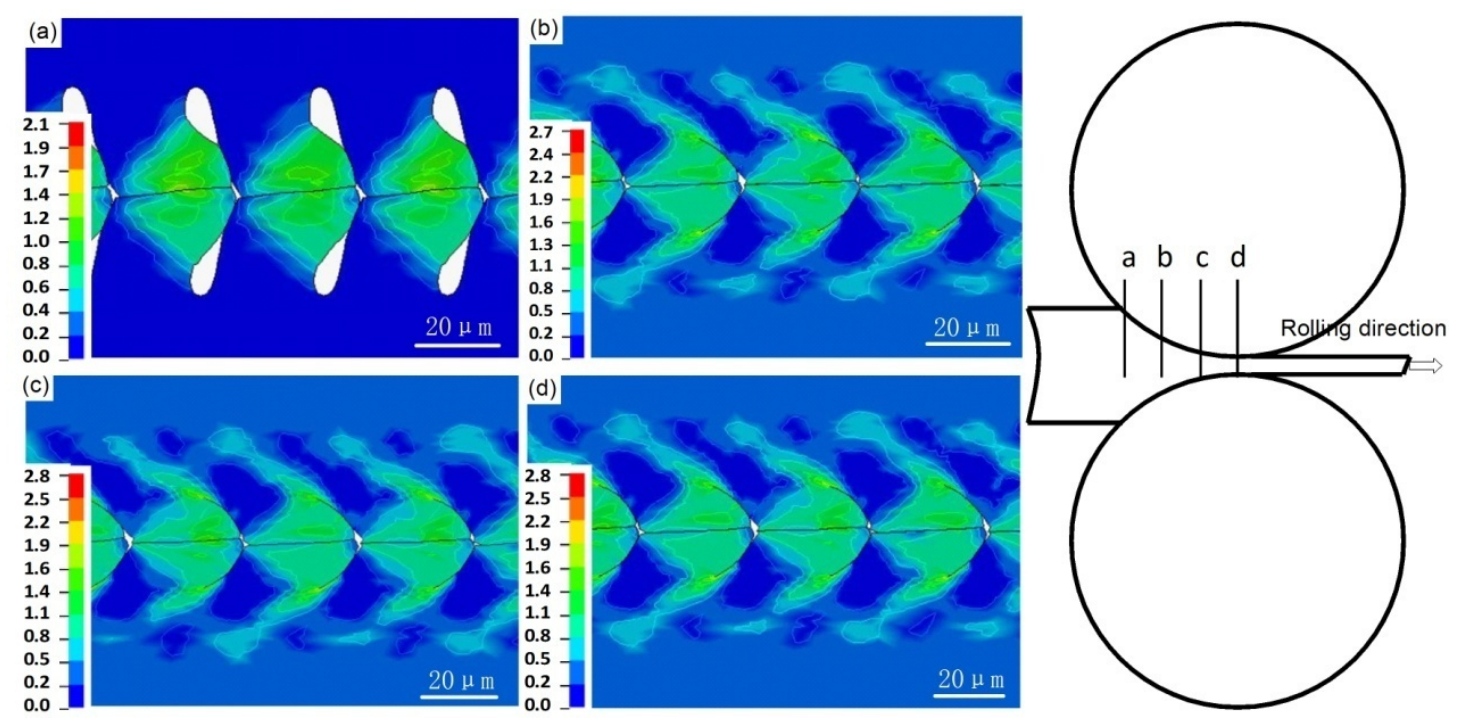

Fig. 4 Crack closure and equivalent strain distribution of internal crack at different cross sections in the roll-plate contact region
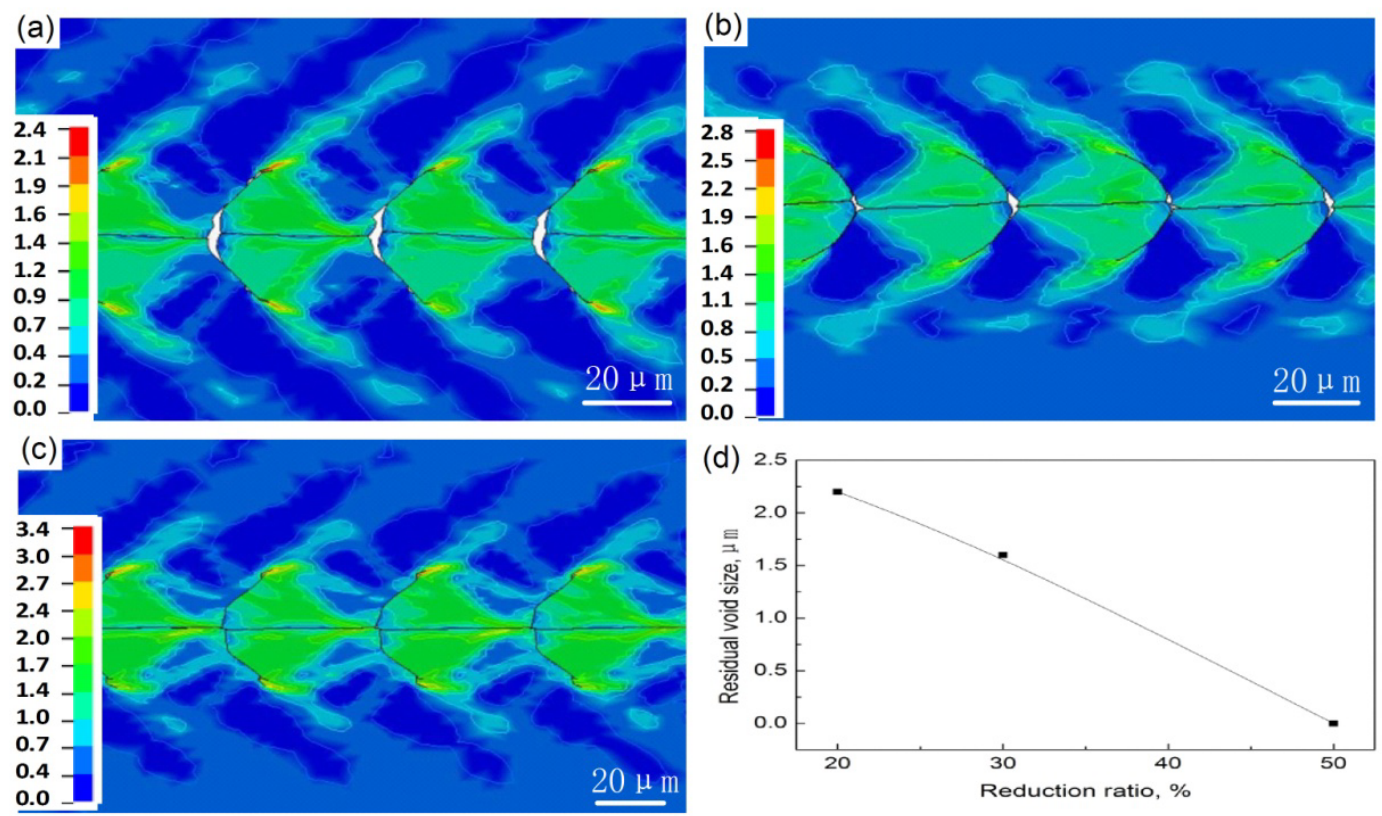

Fig. 5 Shape of residual voids and equivalent strain distribution of cracks after rolling under rolling reduction (a) $20 \%$, (b) $30 \%$, (c) $50 \%$, and (d) residual void size vs reduction ratio 
Fig. 6 shows the characteristic features of internal cracks when the reduction ratio is $20 \%$ for various assumed initial crack depth values. When the initial crack roughness depth is $1 \mu \mathrm{m}$, the crack closes well after rolling and it is very difficult to find traces of residual voids, as shown in Fig. 6 (a). When the roughness depth is $4 \mu \mathrm{m}$, a few voids are revealed in the workpiece after rolling. However, when the initial crack roughness is $24 \mu \mathrm{m}$, the crack does not close well; there are many large residual voids, as shown in Fig. 6 (c). From these simulated results, it can be concluded that the number and size of residual voids in workpiece after rolling increases with the crack surface roughness, as shown in Fig. 6 (d). During the rolling process, the equivalent strain around the cracks increases with the crack wave depth. When the crack wave depth is $1 \mu \mathrm{m}$, the maximum equivalent strain is 0.45 . And when the crack wave depth increases to $24 \mu \mathrm{m}$, the maximum equivalent strain reaches 2.4 .
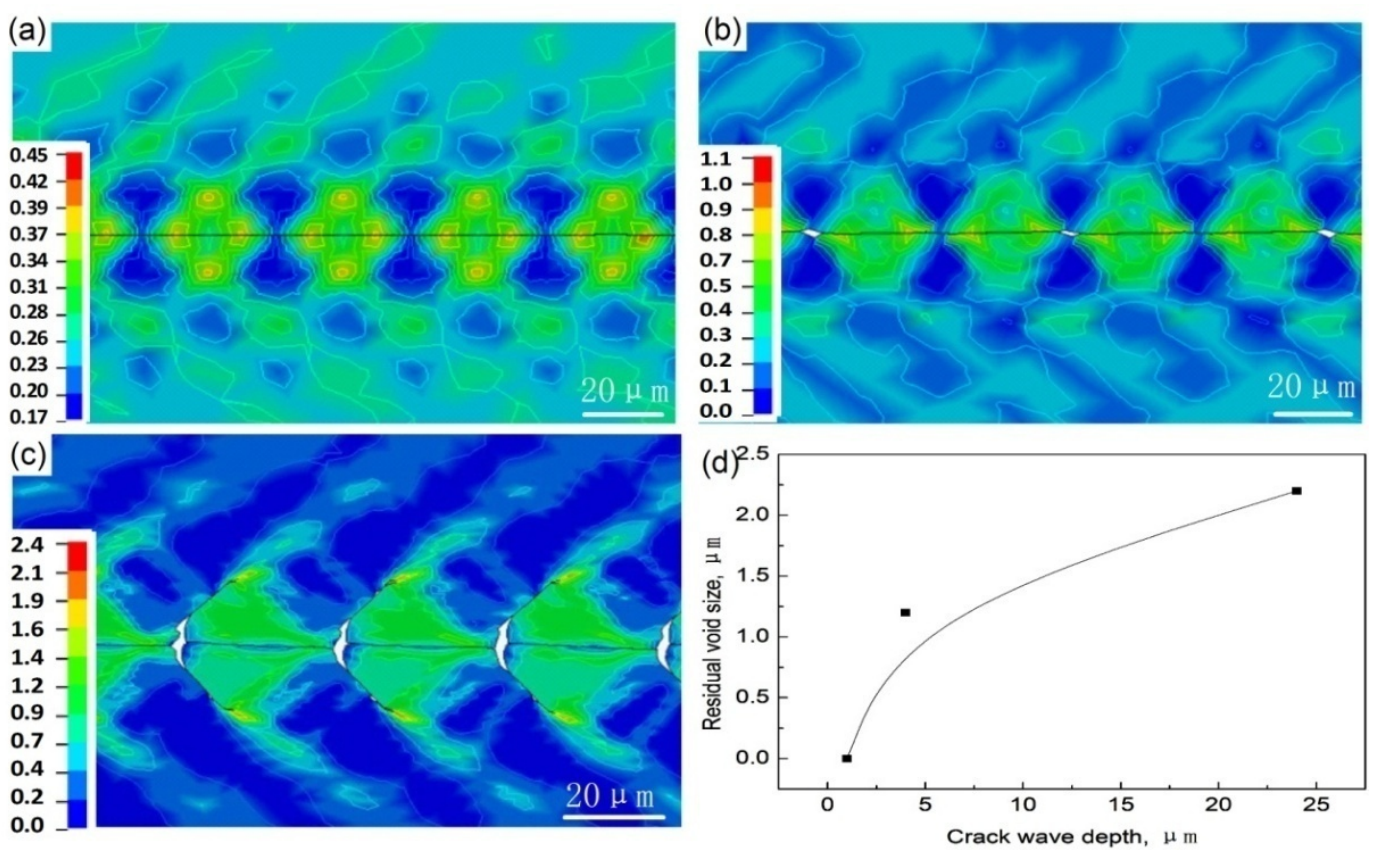

Fig. 6 Shape of residual voids and equivalent strain distribution in the crack region after rolling for

different crack profile depths (a) $1 \mu \mathrm{m}$, (b) $4 \mu \mathrm{m}$, (c) $24 \mu \mathrm{m}$; and (d) residual voids size vs crack profile depth

Fig. 7 shows experimental results of crack healing when the reduction ratio is $5 \%, 20 \%$ and $50 \%$. These results were obtained on an experimental rolling mill with carbon steel specimens with the chemical composition C 0.15 , Si $0.307, \mathrm{Mn} 1.33$. The diameter of the work roll is 450 $\mathrm{mm}$, and the rolling temperature is in the range of $1150^{\circ} \mathrm{C}-1160^{\circ} \mathrm{C}$. Although the chemical composition of the carbon steel used in FE model is slightly different from the experimental 
carbon steel, the yield stress of the experimental steel is expected be close to that in FE model. The surface roughness of the preset crack is Ra1.6. When the reduction ratio is $5 \%$, the crack surfaces do not contact each other, which keep the initial crack surface conditions, as shown in Fig. 7 (a). When the reduction ratio is $20 \%$, there are many residual voids at the preset crack location, as shown in Fig.7 (b). The size of residual voids is in the range of $1.6 \mu \mathrm{m}$ to $2 \mu \mathrm{m}$. This experimental observation agrees well with the simulation result corresponding to an initial crack roughness depth of $4 \mu \mathrm{m}$ and $24 \mu \mathrm{m}$, as shown in Fig. 6 (b) and (c). The size of residual voids is about $1.2 \mu \mathrm{m}$ for the model with initial crack roughness depth $4 \mu \mathrm{m}$, and $2.2 \mu \mathrm{m}$ for the model with initial crack roughness depth $24 \mu \mathrm{m}$. However, there are no residual voids in Fig. 6 (a) in which the initial crack roughness depth is only $1 \mu \mathrm{m}$. When the reduction ratio is $50 \%$, it is difficult to notice any residual voids as shown in Fig. 7(c), indicating in good agreement with the simulation result in Fig. 5 (c).
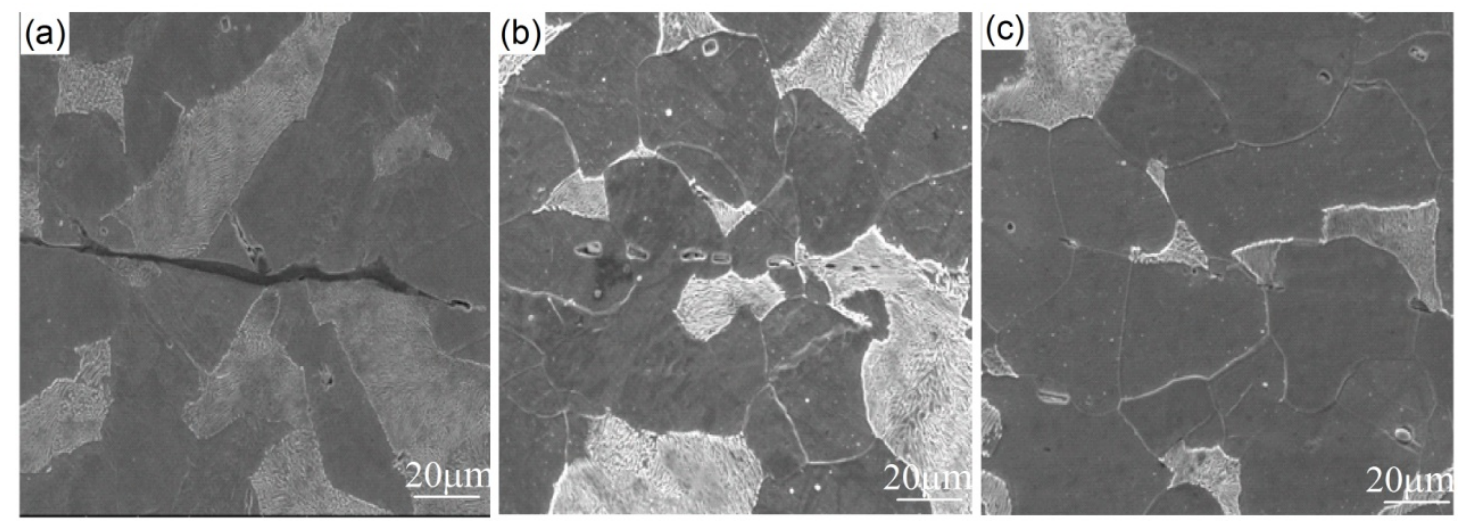

Fig. 7 Experimental results of crack healing after rolling under reduction ratio (a) $5 \%$, (b) $20 \%$ and (c) $50 \%$

\section{Discussion}

Residual defects after hot rolling result in a degradation of the product quality. Many studies on the closure of cracks and voids in rolled products have been carried out. Some studies show that high friction, large roll radius and high reduction ratios are conducive to the closure of defects in hot rolling [25, 26]. However, these defects are assumed to be V-shape [4-9], rectangular [1, 10, 34], elliptical [21-24], or circular [25-29]. For these shapes, the closure mechanisms are listed in Table 1. Voids of such shapes undergo closure under certain reduction ratios. Deng et al [1] found that a rectangular crack closed well when the reduction ratio is larger than $13.9 \%$ for $140 \mathrm{~mm}$ thick ultra-heavy plates. Zhang et al [34] found that the threshold value of the rolling reduction 
ratio is $15.8 \%$ to ensure closure of rectangular-shape cracks in $400 \mathrm{~mm}$ thick continuous slabs. Fig. 6 (a) presents similar findings. For circular voids, Stahlberg and Keife [25] reported a 64\% reduction in void height after a rolling reduction of $18 \%$. Such large voids are difficult to close due to their initial size $[\mathbf{2 5}, \mathbf{3 5}]$. However, it is obvious that they cannot explain the appearance of residual voids in samples when the reduction ratio is $20 \%$ as shown in Fig. 7 (b). As shown in Fig. 1 and Fig. 7 (a), the surface of the actual cracks is rough. This will directly affect the residual void size and distribution. The crack will close well without residual voids when the crack surface has a small roughness as shown in Fig. 6(a). When the crack surface roughness depth increases to $4 \mu \mathrm{m}$ or $24 \mu \mathrm{m}$, the simulated results can be used to explain the phenomenon of residual voids after rolling. The newly proposed model is more comprehensive and will overcome the shortcomings of the models listed in Table 1.

Table 1. Closure mechanism for single shape defects

\begin{tabular}{|c|c|}
\hline Defect shape & Closure of defects \\
\hline V-shape & $\Longrightarrow$ \\
\hline Rectangular & $D \Longrightarrow=$ \\
\hline Ellipse & \\
\hline Circle & \\
\hline
\end{tabular}

In this paper, our models focus on the effect of crack surface roughness. During rolling deformation, healing is initiated by the roughness peaks on opposite sides of the crack surface coming into contact. The internal crack thus assumes the form of many voids separated by contacts between the roughness peaks. In the rolling deformation zone, both compressive deformation and shear deformation occur in plates. It is very difficult to control a local zone deformation, which is accompanied by complex crack roughness peak movement. Fig. 8 shows possible alternative steps in peak movement mechanisms. Fig. 8 (a) shows a movement of the deformed peaks towards the left, and Fig. 8(b) shows a movement towards the right. When the roughness peaks come into contact with each other, two kinds of voids are formed at positions $\mathrm{P}_{1}$ 
and $\mathrm{P}_{2}$ in Fig. 8 (a). With higher deformation, the void $\mathrm{P}_{2}$ gradually decreases (Fig. 4(b)). When the reduction ratio is larger than $20 \%$, the voids at $\mathrm{P}_{2}$ closes well, as is also shown in Fig. 5. However, the voids in the $\mathrm{P}_{1}$ positions resist closure. In Fig. 8 (c) the roughness peaks move towards each other, while in Fig. 8(d) the roughness peaks move in away from each other. Movement such as in Fig. 8 (c) is conductive to void closure. However, for the case in Fig. 8 (d), such peak movement may result in larger residual voids in the workpiece after rolling, as indicated by ' $\mathrm{P}_{3}$ '. Because in any actual rolling process, the four mechanisms may occur simultaneously, the voids could be non-uniformly distributed in the workpiece during rolling process.
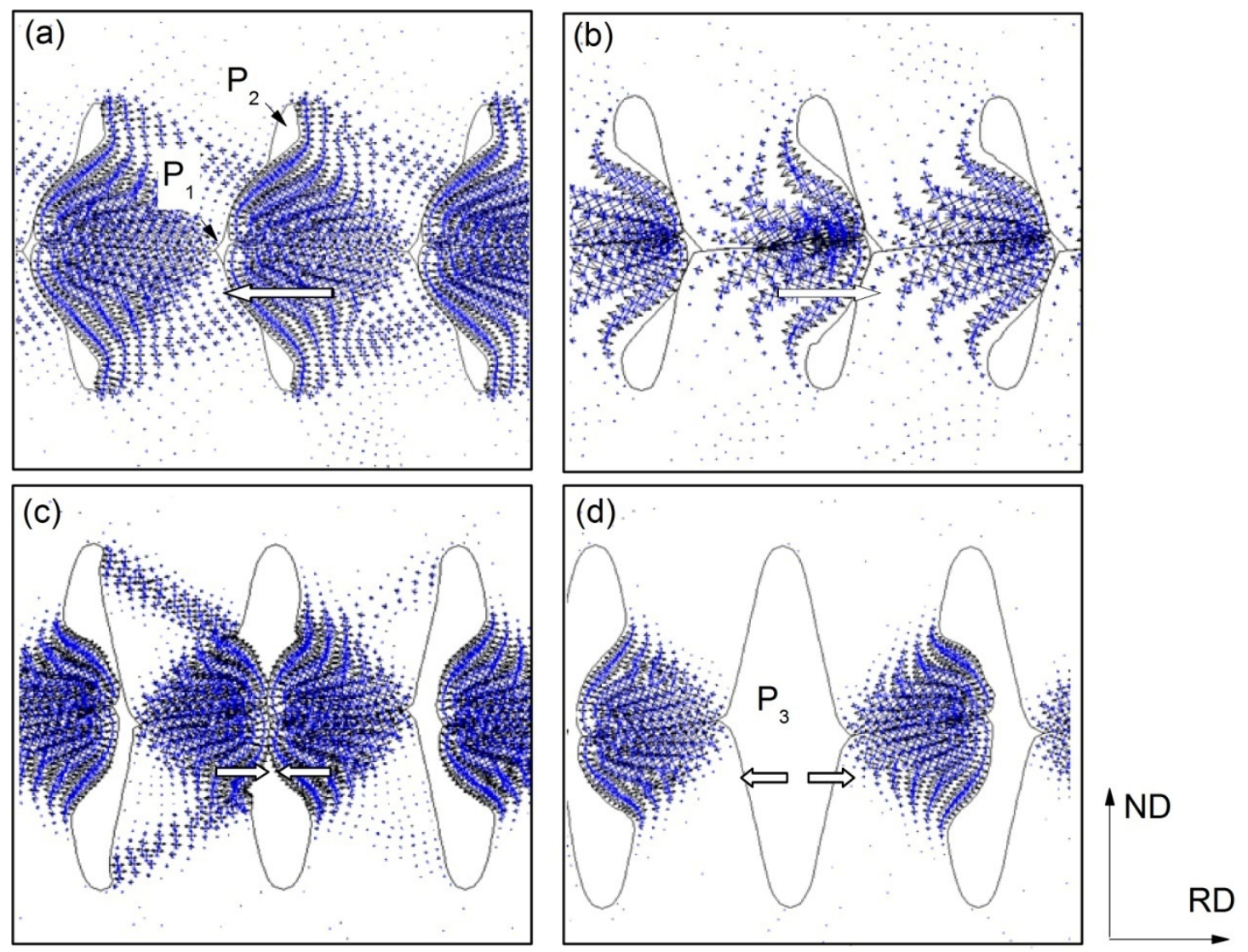

Fig. 8 Movement of roughness peak in deformation (RD- parallel to rolling direction, ND-Normal to rolling direction), (a) and (b) movement along left and right side, (c) and (d) movement along opposite directions

The strain change during rolling in the deformation zone is shown in Fig. 9. After rolling, the maximum strain appears in the wave trough zone for both $20 \%$ and $30 \%$ reduction ratios. The mean value of the strain when the reduction ratio is $20 \%$ is less than that for the $30 \%$ reduction ratio. When the reduction ratio is $20 \%$, the minimum strain appears at ' $\mathrm{P} 10$ ', where there is still a 
void after rolling, as shown in Fig. 5 (a). When the reduction ratio is 30\%, the strains at P1, P8 and P9 are less than that at other positions. These strain levels are less than 0.6 , which may explain why some small voids persist in the workpiece after rolling, as shown in Fig. 5 (b). It is also seen that the strain near the peak of the roughness profile is less than that near the trough. In addition, the strain in the trough region is still non-uniform. The large difference in strain at P5 and P6 may result in residual voids in the trough zone.

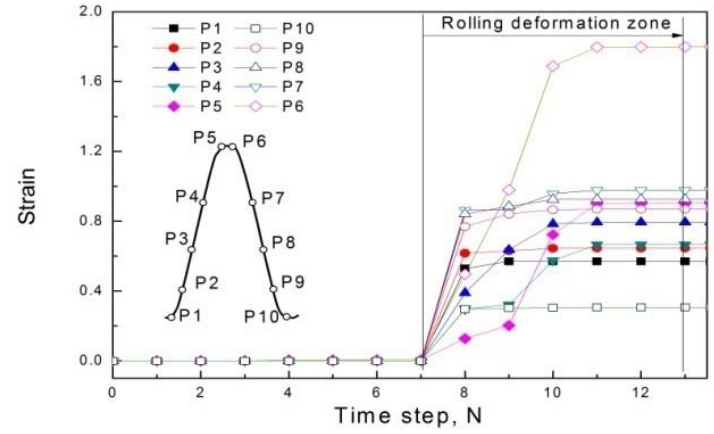

(a)

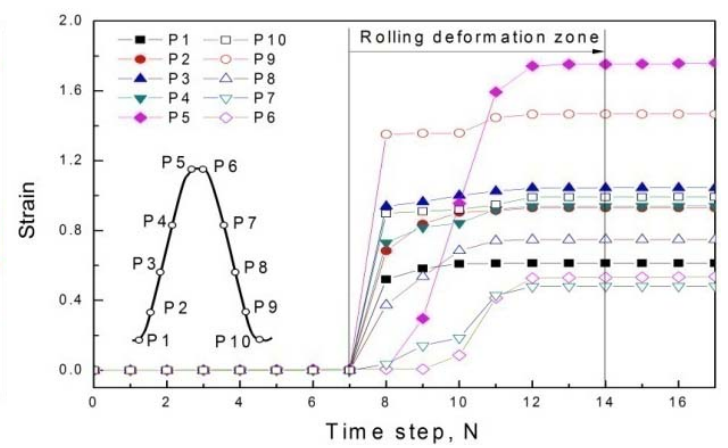

(b)

Fig. 9 Strain at different points on the roughness profile during rolling, for two reduction ratios: (a) $20 \%$ and (b) $30 \%$

Chen et al [36] developed a mathematical model for the diffusion bonding between two pieces of the same materials. Their model shows that plastic deformation plays a major role in the diffusion bonding process. It is obvious that the bonding strength increases with increasing crack surface pressure and decreasing void size. Although the void shape after rolling in Fig. 6 (b) and (c) is different from that in Fig. 7 (b), such shape change mainly occurs after rolling. In comparison to a workpiece without defects, the residual voids generate a free energy delta of the system in the material. Based on the minimum energy principle, to seek a way to make free energy reduced is useful for void elimination in the system. In addition, owing to the stress gradient around the residual voids and the high temperature of the samples, voids of randomly generated shapes (Fig. 6(c)) will transform into small circular voids through the surface source mechanism, interface source mechanism, and creep mechanism [36-38], as shown in Fig. 7 (b). The transformation of the void shape enables effective crack healing. In addition, there are some other factors that might affect the crack closure and healing such as strain rate [39], which is related to 
the rolling speed. As seen in Ref. [39], with a decreasing strain rate, the crack healing condition improves greatly.

\section{Conclusions}

(1) An FE rolling model for internal crack closure is presented, with consideration of the effect of crack surface roughness on the healing process. The simulation results compare well with experimental results.

(2) There appear to be four kinds of relative motions of the roughness peaks during the plastic deformation process. Consideration of the crack surface roughness allows formulation of a better explanation of residual voids in the workpiece after rolling.

(3) In the rolling process, most of the voids reside in the vicinity of peaks and troughs of the roughness elements. Greater crack surface roughness results in a greater number of residual voids in the workpiece after rolling. In addition, the cracks close better with increasing rolling reduction ratio.

\section{Acknowledgments}

The lead author gratefully acknowledges the financial support from the Vice-Chancellor's Fellowship Grant at the University of Wollongong, the National Natural Science Foundation of China through Grant 51105071 and the Doctorate Foundation of the Ministry of Education of China through the Grant 20090042120005.

\section{References}

[1] Deng W, Zhao DW, Qin XM, et al (2009) Simulation of central crack closing behavior during ultra-heavy plate rolling. Comp Mater Sci 47: 439-447.

[2] Brimacombe JK, Sorimachi K (1977) Crack formation in the continuous casting of steel. Metall Trans B 8: 489-505.

[3] Chang GW, Jin GC, Chen SY, et al (2007) Research on the formation mechanism of internal crack in the continuous casting slab. Acta Metall Sin (Engl Lett) 20: 35-39.

[4] Norden K, Jonsson S (2007) A study of surface deformation during wire-rod rolling of high speed steels using experimental and computational techniques. Steel Res Int 78: 876-863.

[5] Son IH, Lee JD, Choi S, et al (2008) Deformation behavior of the surface defects of low carbon steel in wire 
rod rolling. J Mater Process Technol 201: 91-96.

[6] Yu HL, Liu XH, Ren XJ (2008) Behavior of longitudinal cracks on slab surfaces in V-H rolling process. Steel Res Int 79: 536-542.

[7] Awais M, Lee HW, Im YT, et al (2008) Plastic work approach for surface defect prediction in the hot bar rolling process. J Mater Process Technol 201: 73-78.

[8] Pesin A, Salganik V, Pustovoytov D (2010) Transverse crack modeling of continuously casted slabs through finite element method in roughing rolling at wide strip mill. AIP Conf Proceedings1252: 1309-1315.

[9] Ervasti E, Staglberg U (2000) Transversal cracks and their behavior in the hot rolling of steel slabs. J Mater Process Technol 101: 312-321.

[10] Yukawa N, Ishikawa T, Yoshida Y, et al (2005) Influence of rolling condition on deformation of surface micro-defect in plate rolling. J Iron Steel Inst Jp 91: 861-867.

[11] Yu HL, Liu XH (2009) Thermal-mechanical finite element analysis of evolution of surface cracks during slab rolling. Mater Manuf Process 24: 570-578.

[12] Yu HL, Tieu K, Lu C, et al. (2013) Occurrence of surface defects on strips during hot rolling process by FEM. Int J Adv Manuf Tech 67: 1161-1170.

[13] Xie HB, Jiang ZY, Wei DB, et al (2010) Study on edge crack propagation during cold rolling of thin strip by FEM. AIP Conf Proceedings 1252: 1320-1325.

[14] Na DH, Lee Y (2008) FE simulation of edge crack initiation and propagation of conventional grain orientation electrical steel. Int J Mod Phys B 22: 5465-5470.

[15] Hubert C, Dubar L, Dubar M, et al (2012) Finite element simulation of the edge-trimming/cold rolling sequence: analysis of edge cracking. J Mater Process Technol 212: 1049-1060.

[16] Kainz A, IIie S, Parteder E, et al (2008) From slab corner cracks to edge-defects in hot rolled stripexperimental and numerical investigations. Steel Res Int 79: 861-867.

[17] Riedel H, Andrieux F, Walde T, et al (2007) The formation of edge cracks during rolling of metal sheet. Steel Res Int 78: 818-824.

[18] Ghosh S, Li M, Gardiner D (2004) A computational and experimental study of cold rolling of aluminum alloys with edge cracking. J Manuf Sci Eng 126: 74-82.

[19] Yu HL, Liu XH, Li CS, et al (2009) Research on the behavior of transversal crack in slab V-H rolling process by FEM. J Mater Process Technol 209: 2876-2886.

[20] Sun CG, Kim JW, Hwang SM (2003) Investigation of the thermo-mechanical behavior of type 304 stainless 
slab in hot charge rolling condition by the finite element method. ISIJ Int 43: 1773-1780.

[21] Nakasaki M, Takasu I, Utsunomiya H (2006) Application of hydrostatic integration parameter for free-forging and rolling. J Mater Process Technol 177: 521-524.

[22] Jeong C, Yanagimoto J (2013) Application of damage model with material flow evaluation to high temperature compression processes. Mod Phys Lett B 26: 1150012.

[23] Zhang XX, Ma F, Ma K, et al (2012) Multi-scale analysis of void closure for heavy ingot hot forging. Mod Appl Sci 6: 15-25.

[24] Zhang XX, Cui ZS, Chen W, et al (2009) A criterion for void closure in large ingots during hot forging. J Mater Process Technol 209: 1950-1959.

[25] Stahlberg U, Keife H (1992) A study of hole closure in hot rolling as influenced by forced cooling. J Mater Process Technol 30: 131-135.

[26] Wallero A (1985) Closing of a central longitudinal pore in hot rolling. J Mech Work Technol 12: 233-242

[27] Kakimotoa H, Arikawaa T, Takahashib Y, et al (2010) Development of forging process design to close internal voids. J Mater Process Technol 210: 415-422.

[28] Lee YS, Kwon YC, Kwon YN, et al (2007) Analysis on void closure behavior during hot open die forging. Adv Mater Res 26-28: 69-72.

[29] Chen J, Chandrashekhara K, Mahimkar C, et al (2012) Study of void closure in hot radial forging process using 3D nonlinear finite element analysis. Int J Adv Manuf Technol 62: 1001-1011.

[30] Orhan N, Aksoy M, Eroglu M (1999) A new model for diffusion bonding and its application to duplex alloys. Mater Sci Eng A271: 458-468.

[31] Bross P, Exner HE (1979) Computer simulation of sintering processes. Atca Metall 27: 1013-1020.

[32] Li Y, Liu JX, Ke XT (2009) Development and research of deformation resistance model in hot rolling process. Res Iron Steel, 37: 59-62.

[33] http://www.metalpass.com/metaldoc/paper.aspx?docID=145

[34] Zhang L, Zhao DW, Deng W, et al (2011) Simulation of central defects closing during $400 \mathrm{~mm}$ thickness continuous casting slab rolling. Iron Steel 46: 61-65+76.

[35] Hwang YM, Chen DC (2002) Finite element simulation on void closure behavior inside the sheet during sheet rolling process. P I Mech Eng B J Eng 216: 1227-1237.

[36] Chen HY, Cao J, Song XG, et al (2012) Contributions of atomic diffusion and plastic deformation to the plasma surface activation assisted diffusion bonding of zirconium-based bulk metallic glass. Appl Phys Lett 100: 
211602.

[37] Derby B, Wallach ER (1982) Theoretical model for diffusion bonding. Metal Sci 16: 49-56.

[38] Ma RF, Li Q, Li H, et al (2012) Modeling of void closure in diffusion bonding process based on dynamic conditions. Sci China Tech Sci 55: 2420-2431.

[39] Yu HL, Liu XH, Li XW, Godbole A (2014) Crack healing in a low-carbon steel under hot plastic deformation. Metall Mater Trans A 45: 1001-1009. 